\title{
Grouting Technique for Gob-Side Entry Retaining in Deep Mines
}

\author{
Xianyang Yu $\mathbb{D}^{1,2}$ Zhihong Sun,,2 Min Deng, ${ }^{1,2}$ and Jinlin Xin ${ }^{1,2}$ \\ ${ }^{1}$ Hunan Provincial Key Laboratory of Safe Mining Techniques of Coal Mines, Hunan University of Science and Technology, \\ Xiangtan 411201, China \\ ${ }^{2}$ Work Safety Key Lab on Prevention and Control of Gas and Roof Disasters for Southern Coal Mines, \\ Hunan University of Science and Technology, Xiangtan 411201, China
}

Correspondence should be addressed to Xianyang Yu; 1010092@hnust.edu.cn

Received 8 April 2021; Accepted 4 May 2021; Published 13 May 2021

Academic Editor: Zhijie Zhu

Copyright (C) 2021 Xianyang Yu et al. This is an open access article distributed under the Creative Commons Attribution License, which permits unrestricted use, distribution, and reproduction in any medium, provided the original work is properly cited.

\begin{abstract}
The retained rib displacement accounts for roughly $80 \%$ of rib-to-rib convergence in gob-side entry retaining in deep coal mines, which shows significant nonsymmetrical feature and long-term rheological phenomenon. Affected by mining-induced stress, cracks spread widely, and broken zones expand beyond the anchoring range. Without grouting and supplementary support in retained rib, the surrounding rock-support load-bearing structure will be in a postpeak failure state, and the anchoring force of the bolting system will be greatly attenuated. After grouting, the compressive strength of grouting geocomposite specimen is significantly higher than the postpeak residual strength of the intact coal specimen, and it is partially restored compared to that of the intact coal specimen. The ductility of the fractured coal specimen increases after grouting, and it has stronger elasticity and plasticity. Broken rock block can become a whole with coordinated bearing capacity, and its stability is improved after grouting. The grouting technique could restore the integrity and strength of the fractured retained coal rib, repair the damaged bolting structure, and make the surrounding rock and supporting structure become an effective bearing structure again. The research result shows that it is feasible to restore the bearing capacity of the retained coal rib by grouting technique.
\end{abstract}

\section{Introduction}

Gob-side entry retaining is a technique to maintain the original roadways along the gob edges after coal mining. Gob-side entry retaining can improve the coal recovery rate, reduce the excavation rate, and reduce the probability of rock burst, which is an important technology to achieve continuous mining without coal pillars. Its technical advantages and economic benefits are significant [1-3]. Under the rapid development of surrounding rock control theories, coal mining equipment, support techniques, and support materials, gob-side entry retaining has been successfully applied under various conditions [4-9].

Under the influence of high in situ stress and mininginduced stress, it is difficult to maintain the retained roadway in deep coal mines [7, 10]. During the long-term rotation and subsiding of the main roof above the retained roadway, the original cracks in the surrounding rock gradually expand, and new cracks appear at the same time. The surrounding rock is loose, is broken, and has a large amount of deformation and long-term rheology [11]. In this process, the loose and broken surrounding rock of the retained coal rib is the weakest part of the whole roadway, and largedeformation often occurs in this part, which may even affect the stability of the whole roadway $[12,13]$. Maintaining the bearing capacity of the retained coal rib has an important effect on the overall stability of the surrounding rock of the retained roadway.

In this paper, the surrounding rock deformation characteristics of retained roadway are monitored and summarized. The temporal and spatial development of the cracks in retained coal rib and its influence on bolting support structure are tested and analyzed. The effect of grouting reinforcement on the strength of fractured coal is tested, and the principle of grouting reinforcement to restore the bearing capacity of surrounding rock is proposed. The technique of restoring the load capacity of the fractured coal by grouting has been successfully applied to some filed cases. 


\section{Surrounding Rock Deformation Characteristics}

The surrounding rock deformation observation site is located in the tail roadway of 1252 (1) panel in the Panyidong Mine, which is retained after coal mining. The panel layout is $264 \mathrm{~m}$ wide by $1728 \mathrm{~m}$ long. The elevation of the panel is $-823--738 \mathrm{~m}$, and the ground elevation is $+21.5-+22.1 \mathrm{~m}$. The average thickness of the coal seam is $2.3 \mathrm{~m}$, and the dip angle is $3^{\circ}-9^{\circ}$. The main roof is medium-fine sandstone with a thickness of $0-11.0 \mathrm{~m}$. The immediate roof is composed by mudstone, sandy mudstone, and 11-3 coal seam, with a thickness of $0-8.4 \mathrm{~m}$. The surrounding rock deformation of retained roadway is shown in Figure 1. The surrounding rock deformation presents the following characteristics:

(1) Roadway deformation presents a significant nonsymmetrical feature, which is mainly caused by the retained coal rib deformation and the floor heave. The retained coal rib deformation accounts for $85 \%$ of the rib-to-rib convergence; and the floor heave accounts for $79 \%$ of the roof-to-floor convergence.

(2) The roadway surrounding rock is in a state of highspeed deforming for a long time under the disturbance of the main roof rotation and subsiding, and it still shows a long-term rheological phenomenon after the main roof structure is stabilized. In deep mines, the retained roadway surrounding rock is loosened and broken under the influence of the mining-induced stress before and after the working face, and its bearing performance is significantly reduced. Surrounding rock has a strong rheological property, which has lower speed and sustained deformation. If proper reinforcement support is not adopted, the damaged area of the roadway will further increase, and even completely lose stability.

\section{Cracks Development in Retained Coal Rib}

3.1. Observation Plan. The development of cracks in coal and rock is one of the characteristics of its stability, and it has always been a research hotspot in the stability of roadway surrounding rock $[14,15]$. Affected by times excavation and mining disturbances, the retained coal rib is loose and broken and deforms in a large area during the service process. The internal cracks of the surrounding rock will develop, and its bearing capacity is reduced. The expansion of the cracks leads to the debonding of the bonding interface between the anchoring agent and the surrounding rock and gradually extends to both sides of the cracks, which causes the axial stress of the bolting structure to decrease exponentially $[16,17]$. This paper uses the observation results of the borescope to reflect the stability of the surrounding rock of the retained coal rib. Studying the development of cracks in the retained coal rib can provide an evaluation of its stability status and optimize the timing of grouting and other reinforcement methods $[18,19]$.

In order to observe the development of the cracks in the retained coal rib along with the advancement of the working face, holes with a depth of $6 \mathrm{~m}$ were drilled at the positions of $50 \mathrm{~m}, 30 \mathrm{~m}, 10 \mathrm{~m}$, and $5 \mathrm{~m}$ in front of the working face, at the working face, and $10 \mathrm{~m}, 20 \mathrm{~m}, 40 \mathrm{~m}, 60 \mathrm{~m}, 100 \mathrm{~m}$ behind the working face along the coal seam inclination. In order to quantitatively describe the development of cracks in the holes, referring to other research results, coal bodies and cracks are divided into the following four categories [20]. Various kinds of typical cracks are shown in Figure 2.

(a) Small Crack. The crack is original crack or newly developed with aperture less than $2 \mathrm{~mm}$

(b) Medium Crack. Affected by the mining-induced stress, the aperture of the cracks in the coal rib has increased to $2-5 \mathrm{~mm}$

(c) Large Crack. When the coal rib is relatively broken, multiple cracks are connected to each other and gradually expand, and the aperture reaches more than $5 \mathrm{~mm}$

(d) Broken Zone. Affected by mining-induced stress, a large number of cracks in the surrounding rock of the large-deformation roadway are interconnected with each other, and the range of the broken zone is greatly expanded

\subsection{Development of the Cracks and Its Influence on Anchoring} System. After the borescope was completed, the development of the cracks in the boreholes was sketched, and the result is shown in Figure 3. In order to facilitate statistics and analysis, every $500 \mathrm{~mm}$ width of the broken zone is equivalent to a small crack, a medium crack, and a large crack. Figure 4 shows the final statistical results of the cracks in the drilling hole. The development of cracks in the retained coal rib along with the working face is as follows:

(1) Outside of the mining-induced stress area, the cracks in coal rib are generated within a depth of about $1 \mathrm{~m}$ from the surface. The causes of cracks are mostly the original small cracks, mining-induced stress caused by roadway excavation, and weathering of coal on the roadway surface.

(2) With the advancement of the working face, the roadway surrounding rock fracture gradually penetrated into the coal body. Within the range of 0-30 $\mathrm{m}$ in front of the working face, the high mininginduced stress section, the cracks in coal rib are generated within a depth of about $0-2.8 \mathrm{~m}$ from the surface. The greatly fluctuating mining-induced stress caused a large number of new cracks in the retained coal rib and caused the original cracks to expand further. However, it is worth noting that because the roadway adopts the active strong bolting support method, and the main roof above the roadway has not broken or rotated and subsided, the range of the broken zone in coal rib has not been greatly expanded at this time.

(3) In the 0-40 m mining-induced stress-affected section behind the working face, both the ranges of cracks and the width of the broken zones have increased 


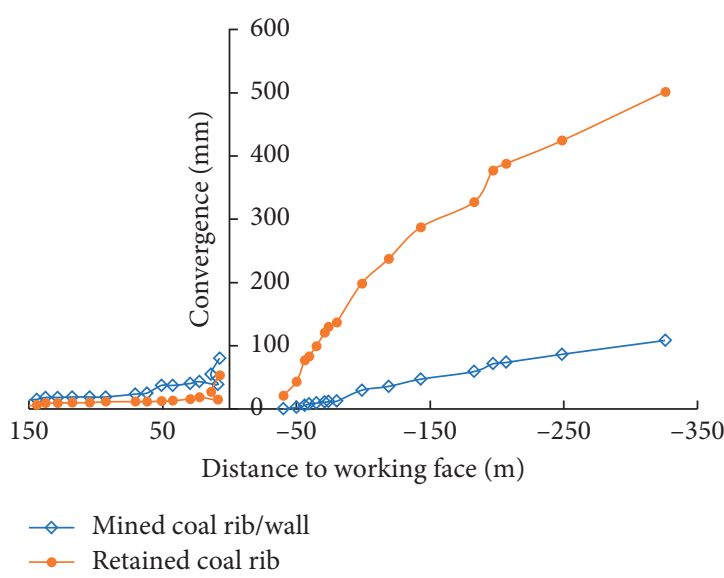

(a)

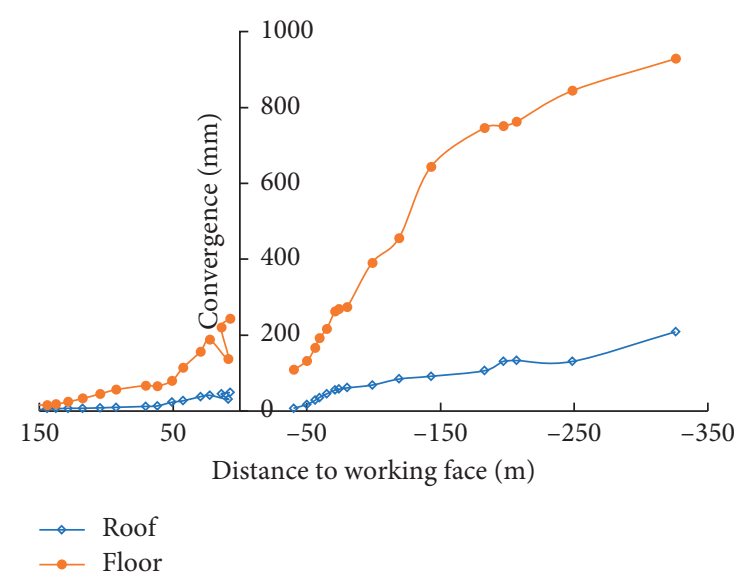

(b)

FIgURE 1: Surrounding rock convergence. (a) Rib/wall convergence. (b) Roof/floor convergence.

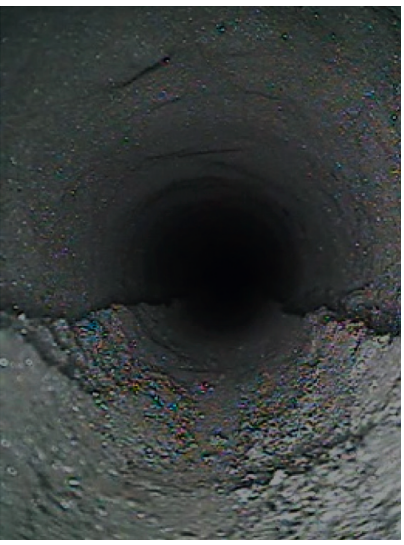

(a)

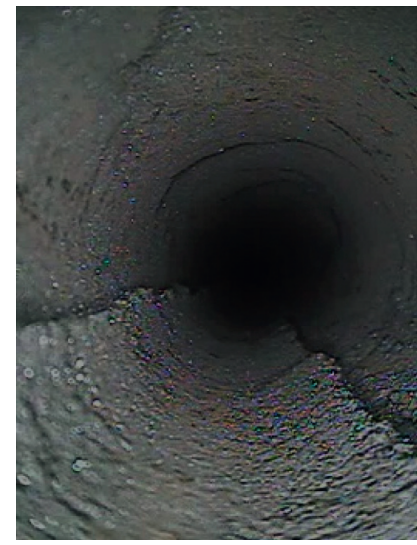

(b)

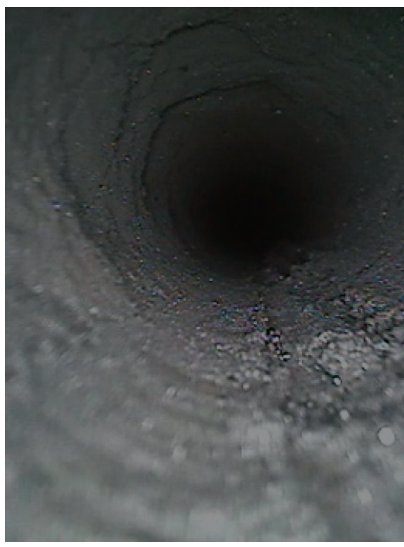

(c)

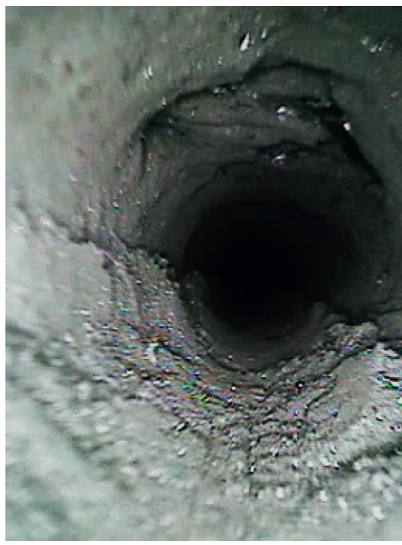

(d)

Figure 2: Typical cracks in borehole images. (a) Small crack. (b) Medium crack. (c) Large crack. (d) Broken zone.

significantly, and the broken zone has also begun to appear inside the retained coal rib. After the main roof breaking, rotating, and subsiding, stress concentration occurs in the retained rib, which causes the shallow part of the coal rib to be crushed and squeezed out. At the same time, it also causes the weakening and failure of the bolting structure. At this time, the surrounding rock-supporting loadbearing structure is already in a postpeak failure state. The roadway surrounding rock needs strengthening supporting in time; otherwise, there will be slow and continuous plastic flow in the future.

(4) Beyond $100 \mathrm{~m}$ behind the working face, retained coal rib cracks extend beyond $6 \mathrm{~m}$ depth. It is often found that the broken zone is in the deep part of the surrounding rock, and the cracks width is further increased. At this stage, the surrounding rock of the roadway has been in a loose and broken state, the anchoring force of the bolting system has been greatly attenuated or has been lost, and the roadway is in a state of plastic flow under low supporting force.

\section{Mechanical Properties of Grouted Fractured Coal Mass}

Grouting can bond the broken surrounding rock, improve the overall mechanical properties of the surrounding rock, weaken the stress concentration between the rock blocks, and make the broken surrounding rock reform a bearing structure. By comparing the stress-strain curves of the intact coal mass and the fractured coal mass grouting geocomposite, the mechanical properties of grouted postpeak coal can be obtained, and the effect of grouting reinforcement can be analyzed.

4.1. Experimental Device and Plan. The experiment was carried out on the MTS 815.03 testing machine and the selfmade pressure-bearing grouting device. The self-made pressure-bearing grouting device can produce the fractured coal mass grouting geocomposite specimen by $\Phi 50 \mathrm{~mm} \times 100 \mathrm{~mm}$, as shown in Figure 5 .

The first step of the experiment was a conventional uniaxial compression experiment, which mainly measured 


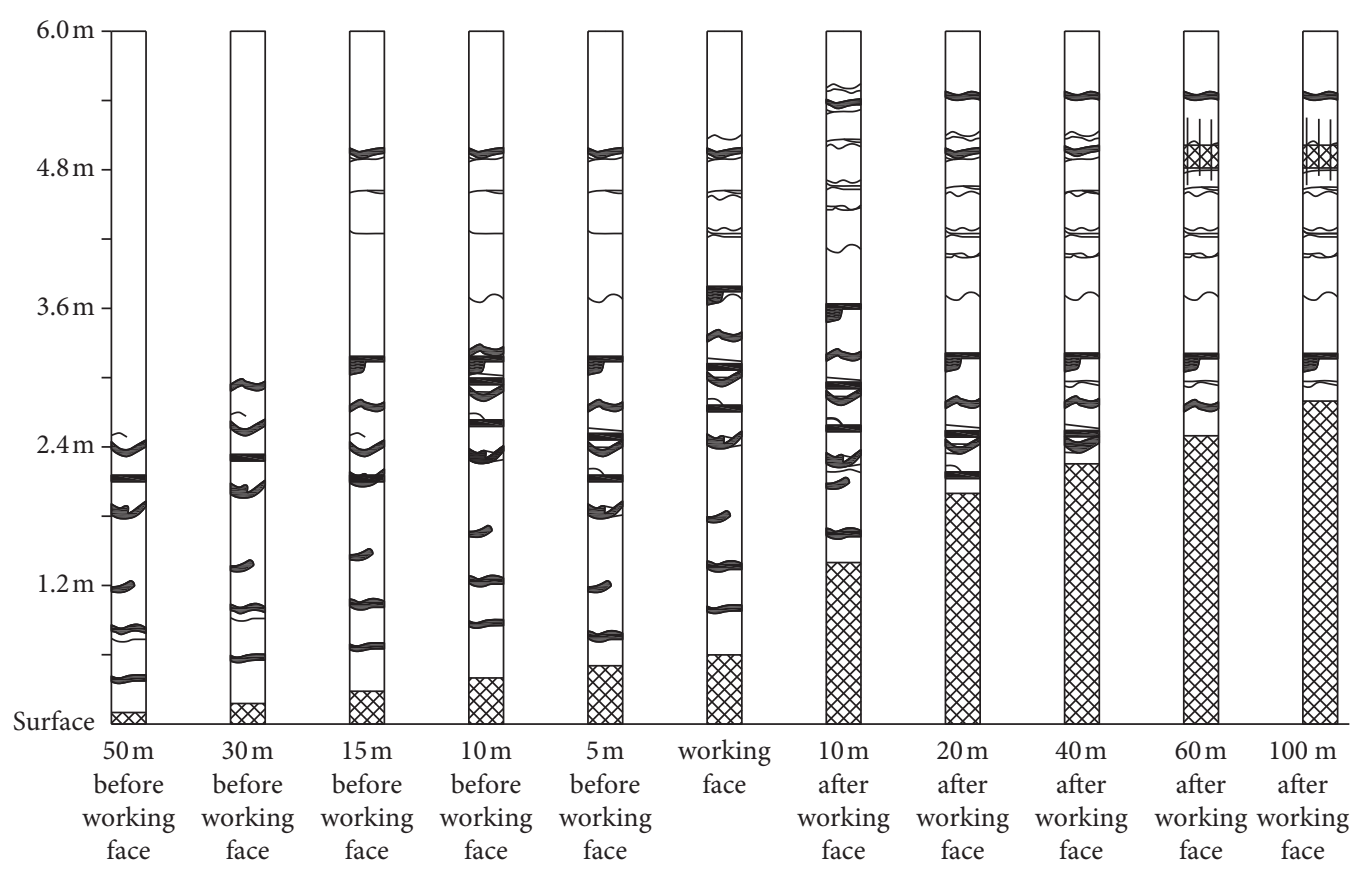

Fracture zone

- Expending cracks

$\sim$ Orginal cracks

FIGURE 3: Sketch of cracks and fractures zones in retained coal rib around working face.

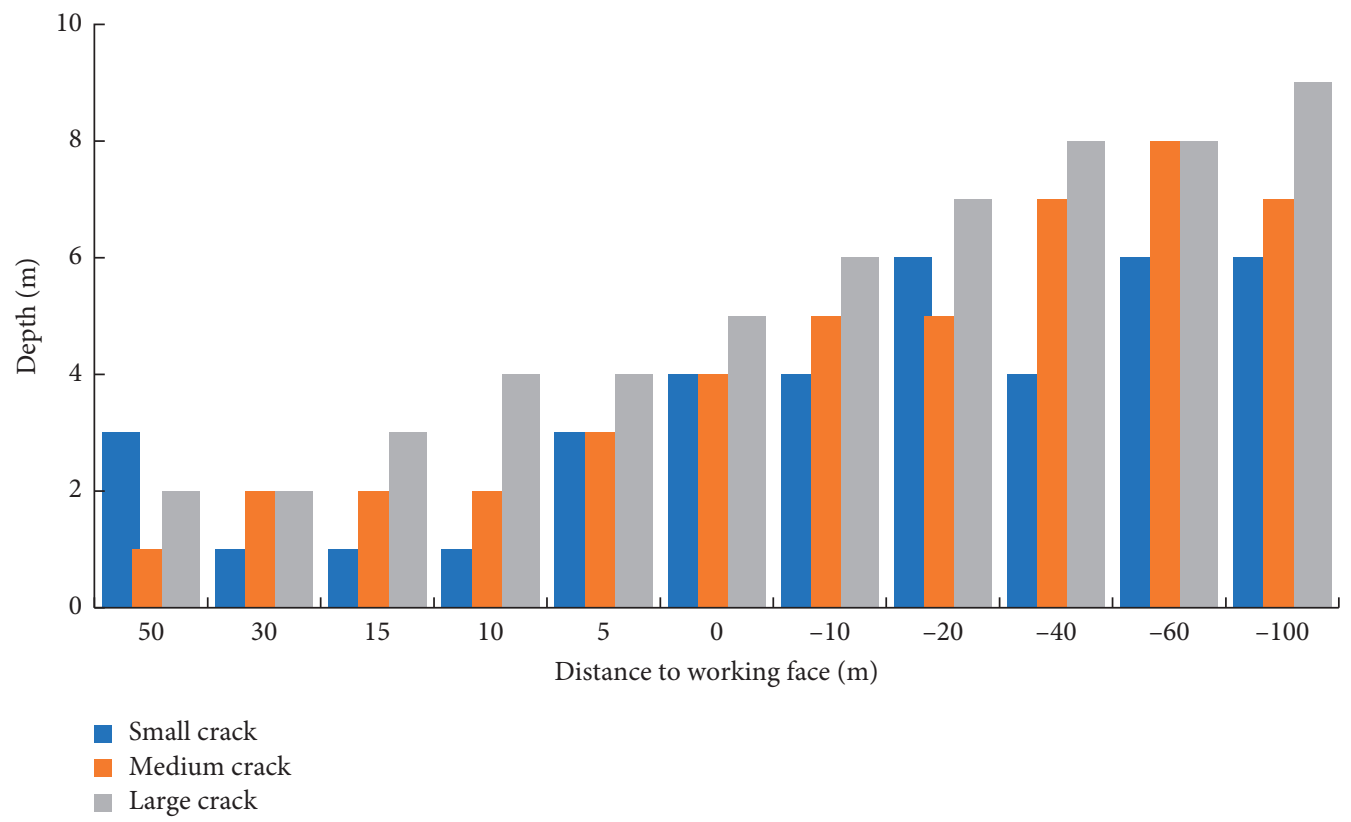

FIGURE 4: Statistical graph of cracks development in boreholes around working face.

the compressive strength and stress-strain curve of the intact coal mass specimen to obtain the mechanical parameters of the intact coal mass specimen. The second step was to prepare the grouting geocomposite specimen. Stirring the cement slurry evenly according to the three water-cement ratios of $0.7,0.8$, and 1.0. Put the specimen that has been fractured in the previous step of the experiment into the pressure-bearing grouting device, and then pour the cement slurry to submerge the specimen. After closing the device cap, start the grouting pump to grout until the pressure reaches $2 \mathrm{MPa}$, and then stop pressurizing. Maintain the pressure until the slurry condenses. Cure at room temperature for 2 to 3 weeks until the cement slurry reaches its maximum strength. Then, trim the grouting geocomposite 


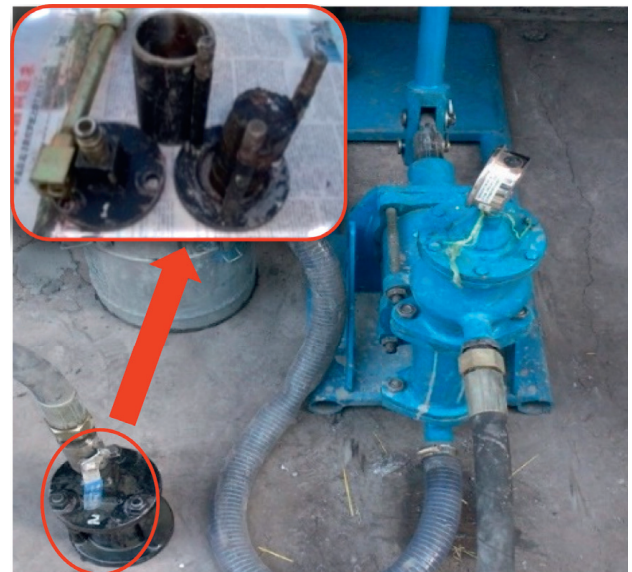

FIgURe 5: Pressure-bearing grouting device.

specimen to make them meet the experimental requirements, as shown in Figure 6.

4.2. Experiment Result and Data Analysis. The ratio of the grouting geocomposite specimen strength to the residual strength of the intact specimen is defined as the consolidation coefficient; the ratio of grouting geocomposite specimen strength to the compressive strength of the intact specimen is defined as the recovery coefficient. In this experiment, the mechanical properties of coal specimen with different P. O42.5 Portland cement water-cement ratios before and after grouting are obtained, as shown in Table 1. Figure 7 shows the stress-strain and Poisson's ratio-strain during the whole loading process of the grouting geocomposite specimen under the condition of 0.8 water-cement ratio. Analyzing the experimental results, we can get the following conclusions:

(1) After grouting, the compressive strength of the grouting geocomposite specimen is significantly higher than the postpeak residual strength of the intake coal specimen, and it is partially restored compared to that of the intact coal specimen. When the water-cement ratio is $0.7,0.8$, and 1.0 , the average consolidation coefficient and recovery coefficient of the grouting geocomposite specimen are 2.84, 2.55, and 1.24 and $35.33 \%, 31.43 \%$, and $40.12 \%$, respectively.

(2) During the whole process from the beginning of the compression to the failure the grouting geocomposite specimen, there is no stress sudden decrease stress after failure of the specimen. It shows that the ductility of the fractured coal specimen increases after grouting, and it has stronger antideformation ability and plasticity.

(3) After the specimen is fractured, the rock blocks slip and move along the fracture surface, the lateral deformation increases rapidly, and its Poisson's ratio $\mu$ increases rapidly. Poisson's ratio $\mu$ of the grouting geocomposite specimen is smaller than that of the intact specimen, which indicates that the broken rock block can become a whole with coordinated bearing capacity, and its stability is improved after grouting.

\section{The Principle of Retained Coal Rib Bearing Capacity Recovered}

5.1. The Principle of Bearing Capacity Recovered. Affected by times excavation and mining disturbances, the original cracks in the retained coal rib are activated, extended and merged, and eventually became internal and surface broken zones. This leads to progressive interface debonding of the anchoring system, which is one of the main forms of bolt support system failure in deep coal mines $[16,17]$. In this situation, the large rib to rib deformation is unavoidable, and large-scale plastic zones and even broken zones appear and develop.

After grouting, the cracks in the retained coal rib at are cemented and filled, the cohesion, internal friction angle, and elastic modulus of the retained coal rib are significantly improved, and the stress concentration in the retained coal rib is greatly weakened. The grouting technique has restored the integrity and strength of the fractured coal rib, repaired the damaged anchoring structure, and made the surrounding rock and supporting structure become an effective bearing structure again [21]. Use the coordinated bearing capacity of bolts and cables to support the surrounding rock. Bolts are used to maintain the shear strength and integrity of the surrounding rock in the shallow surrounding rock. Anchor cables are used to fully utilize the load-bearing capacity of large rock masses with relatively light damage in the deep rock. Under the triple reinforced support of grouting, bolt, and cable, the retained coal rib can effectively resist the impact of mining-induced stress, avoid the continued expansion of cracks, and significantly improve the stability. The stability of retained coal rib has been significantly improved.

5.2. Grouting Opportunity. Research shows that there is an optimal grouting opportunity for grouting in dynamic stress roadway surrounding rock [22-25]. If the grouting is carried out too early, an effective grouting diffusion path has not been formed inside the surrounding rock, and the reinforcement effect will be poor. Under the influence of mininginduced stress, the surrounding rock and supporting structure of the roadway will deform or even be damaged. If the grouting is carried out too late, large-scale loosening and destruction of the surrounding rock of the roadway have appeared, and the bolting and supporting structure have been damaged. At this time, simply relying on grouting can no longer prevent the instability of the roadway.

According to the crack development in retained coal rib and its influence on the bolting structure, grouting can be carried out in the section affected by strong mining-induced stress before and after the working face, in which grouting can achieve the best results at this time. In this section, a large number of cracks have been formed in coal rib, and the broken zone has not been extended beyond the bolting 


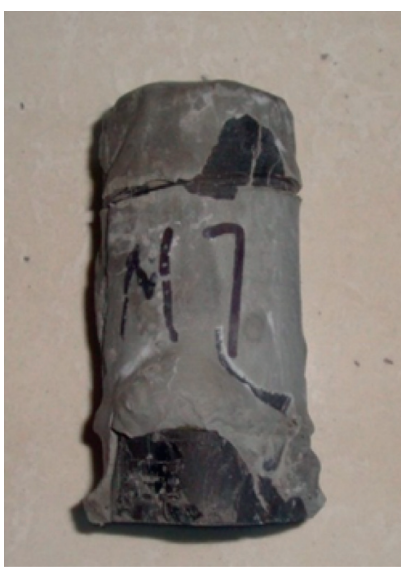

(a)

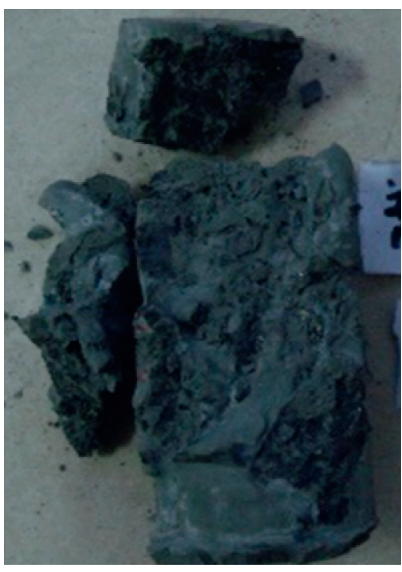

(b)

FIGURE 6: Grouting geocomposite specimen (a) and its broken pieces (b).

TABLE 1: Mechanical properties of coal specimen before and after grouting.

\begin{tabular}{|c|c|c|c|c|c|c|}
\hline No. & $\begin{array}{c}\text { Water- } \\
\text { cement ratio }\end{array}$ & $\begin{array}{c}\text { Intact specimen } \\
\text { UCS }(\mathrm{MPa})\end{array}$ & $\begin{array}{c}\text { Intact specimen residual } \\
\text { strength }(\mathrm{MPa})\end{array}$ & $\begin{array}{l}\text { Grouting geocomposite } \\
\text { specimen UCS }(\mathrm{MPa})\end{array}$ & $\begin{array}{c}\text { Consolidation } \\
\text { coefficient }\end{array}$ & $\begin{array}{c}\text { Recovery } \\
\text { coefficient (\%) }\end{array}$ \\
\hline 1 & & 19.50 & 2.84 & 8.19 & 2.88 & 41.98 \\
\hline 2 & 1.0 & 24.63 & 2.50 & 7.52 & 3.01 & 30.54 \\
\hline 3 & & 16.01 & 2.04 & 5.36 & 2.63 & 33.48 \\
\hline 4 & & 11.45 & 2.73 & 5.33 & 1.95 & 46.54 \\
\hline 5 & 0.8 & 26.74 & - & 0.54 & - & 2.01 \\
\hline 6 & & 22.92 & 3.32 & 10.49 & 3.16 & 45.76 \\
\hline 7 & & 19.19 & 5.37 & 8.83 & 1.64 & 46.02 \\
\hline 8 & 0.7 & 16.51 & 5.80 & 4.65 & 0.80 & 28.19 \\
\hline 9 & & 8.30 & 2.98 & 3.83 & 1.29 & 46.14 \\
\hline
\end{tabular}

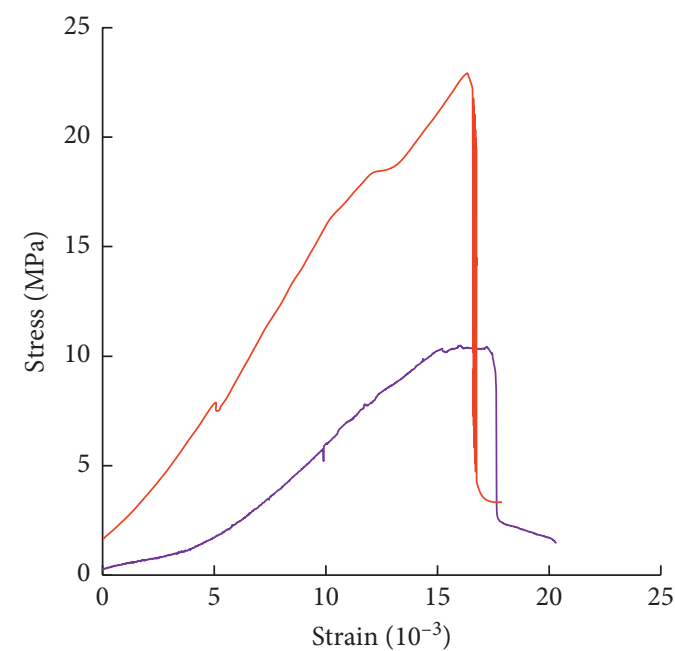

- Grouting geocomposite specimen - Intact specimen

(a)

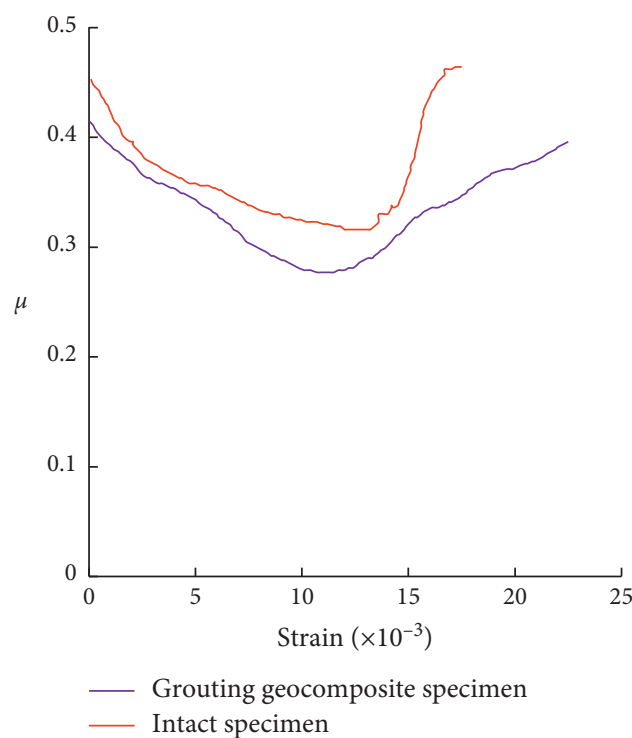

(b)

Figure 7: Mechanical properties of coal specimen before and after grouting. (a) Typical stress-strain curve. (b) Typical Poisson's ratio-strain curve. 


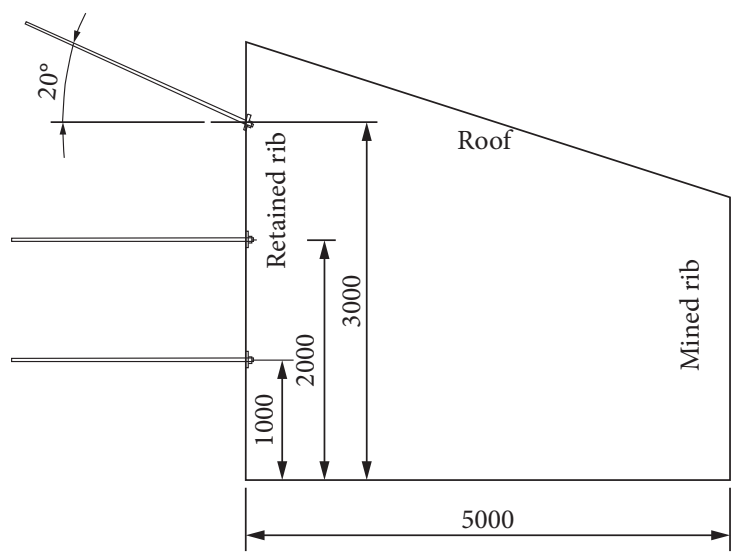

FIGURE 8: Grouting bolts layout.

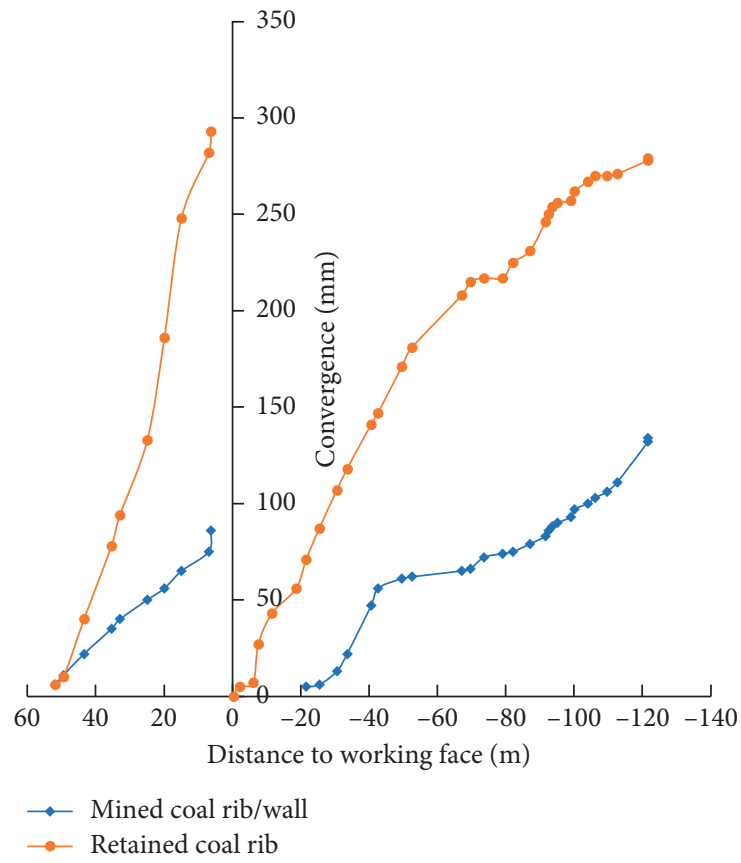

FIgURE 9: Curve of retained roadway ribs displacement.

range. At this time, the interaction between the bolting structure and the surrounding rock is in a critical state, and the bolting system has exerted its maximum supporting effect. Grouting in the strong mining stress affecting section could repair damaged surrounding rock and bolting structure and rebond the broken zones of the surrounding rock. The broken surrounding rock bonded by grouting reforms a bearing unit, which greatly increases the resistance-increasing speed of bolts and cables in large-deformation roadways.

\section{A Field Case}

6.1. Working Panel Situation and Roadway Initial Support. The tail roadway of 12418 panel in the Xieqiao Mine was retained after coal mining. The panel layout is $212.8 \mathrm{~m}$ wide by $826.9 \mathrm{~m}$ long. The elevation of the panel is $-579 \sim-598.8 \mathrm{~m}$, and the ground elevation is $+18.3 \sim+27.1 \mathrm{~m}$. The average thickness of the coal seam is $3.08 \mathrm{~m}$. The main roof of the coal seam is composed of siltstone, medium-fine sandstone, and sandstone, with an average thickness of $5.85 \mathrm{~m}$. The immediate roof is composed by cemented fracture mudstone, sandy with a thickness of $4.56 \mathrm{~m}$.

The roadway has a trapezoidal shape with a width $\times$ height dimension of $5.0 \times 3.0 \mathrm{~m}$, and it was supported by bolts, meshes, and cables. The roof was supported by 7 bolts, the diameter and length of the bolts were $20 \mathrm{~mm}$ and $2500 \mathrm{~mm}$, and the layout is $800 \times 1000 \mathrm{~mm}$. High prestressed anchor cable beams were constructed on the top plate, the diameter and length of the steel strand were $17.8 \mathrm{~mm}$ and $6300 \mathrm{~mm}$, and the layout was "2-2-0-2-2". The retained rib was supported by 5 bolts, the diameter and length of the bolts were $20 \mathrm{~mm}$ and $2500 \mathrm{~mm}$, and the layout was $780 \times 1000 \mathrm{~mm}$. The mined rib was supported by 54 bolts, the diameter and length 


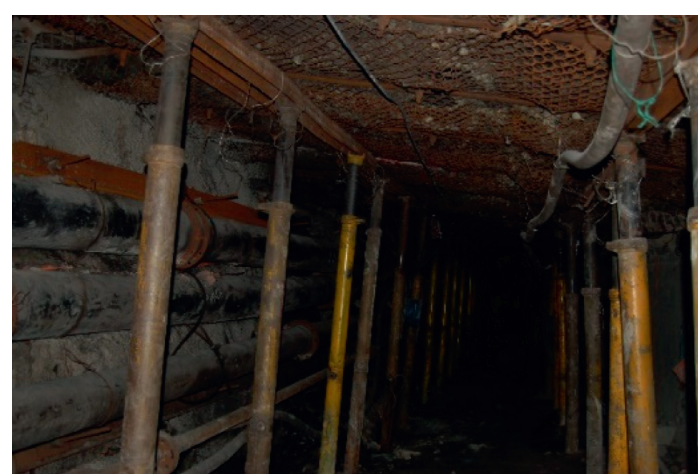

Figure 10: Roadway at $160 \mathrm{~m}$ after working face.

of the bolts were $18 \mathrm{~mm}$ and $2000 \mathrm{~mm}$, and the layout was $730 \times 1000 \mathrm{~mm}$. The width of the filling wall is $3.0 \mathrm{~m}$. The wall is made of ready-mixed concrete, and the main components are cement, fly ash, and sand and gravel aggregates and additives. The measured final setting strength is $25-30 \mathrm{MPa}$.

\subsection{Grouting and Supplementary Support in Retained Coal} Rib. When the roadway was not affected by the mininginduced stress, a row of anchor cable beams was carried out along the roadway direction on the retained rib to control its rapid deformation during the mining. The distance between the anchor cable beam and the roadway floor was $2.5 \mathrm{~m}$, and the diameter and length of the steel strand were $17.8 \mathrm{~mm}$ and $4300 \mathrm{~mm}$, respectively. The drill hole was inclined upward by $40^{\circ}$. Quick-hardening sulphoaluminate cement was adopted for grouting cement, the compressive strength of which can reach $30 \mathrm{MPa}$ in one day and $42.5 \mathrm{MPa}$ in three days. Grouting was carried out $20-30 \mathrm{~m}$ in front of the working face with a water-cement ratio of 0.8 . Three grouting bolts were arranged in each row in the retained rib, the length of the bolts is $2600 \mathrm{~mm}$, and the distance between the bolts was $1.0-2.0 \mathrm{~m}$. The hole sealing length of the grouting holes needs to be $1.0 \mathrm{~m}$, and the grouting pressure was $1.0-1.5 \mathrm{MPa}$. The layout of grouting bolts is shown in Figure 8.

6.3. Retained Roadway Deformation. Grouting and supplementary support in retained roadway have controlled the surrounding rock deformation, as shown in Figures 9 and 10 . In front of the working face, the rib-to-rib convergence was only $300 \mathrm{~mm}$, which provided a foundation for the stability of the retained roadway behind the working face. The retained roadway within the section of $0-40 \mathrm{~m}$ behind the working face was strongly affected by mininginduced stress. The influence of mining-induced stress in the section of $40-90 \mathrm{~m}$ behind the working face gradually weakened, and the deformation speed of the retained rib and wall began to slow down. Outside the section of $100 \mathrm{~m}$ behind the working face, the roof rotated and subsided to a stable state. At this time, the deformation speed of the retained roadway gradually decreased and entered a stable period. After that, the deformation of the retained coal rib is less than $1 \mathrm{~mm}$ per day. Grouting and supplementary support kept the surrounding rock of the roadway intact, and the width and height of the roadway were about $3.6 \mathrm{~m}$ and $2.5 \mathrm{~m}$ respectively.

\section{Conclusion}

(1) The retained roadway deformation presents a significant nonsymmetrical feature. The retained coal rib deformation accounts for most of the rib-to-rib convergence in deep mines.

(2) If proper support method is not adopted, the cracks in the retained rib will gradually increase, and the range of the broken zone will expand from the surface beyond the bolting range. Without grouting and supplementary support in retained rib, the surrounding rock-supporting load-bearing structure will be in a postpeak failure state, and the anchoring force of the bolting system will be greatly attenuated.

(3) After grouting, the compressive strength of the grouting geocomposite specimen is significantly higher than the postpeak residual strength of the intake coal specimen, and it is partially restored compared to that of the intact coal specimen. The ductility of the fractured coal specimen increases after grouting, and it has stronger elasticity and plasticity. Broken rock block can become a whole with coordinated bearing capacity, and its stability is improved after grouting.

(4) The grouting technique could restore the integrity and strength of the fractured coal rib, repair the damaged bolting structure, and make the surrounding rock and supporting structure become an effective bearing structure again. The research result shows that it is feasible to restore the bearing capacity of the retained coal rib by grouting technique.

\section{Data Availability}

All the data generated or published during the study are included within the article; no other data were used to support this study.

\section{Conflicts of Interest}

The authors declare that they have no conflicts of interest.

\section{Acknowledgments}

The authors gratefully acknowledge the funding for this work provided by the National Natural Science Foundation of China (no. 51904102) and Open Foundation of Hunan Provincial Key Laboratory of Safe Mining Techniques of Coal Mines, China (no. E21733). 


\section{References}

[1] Z. Z. Zhang, M. Deng, J. B. Bai, X. Y. Yu, Q. H. Wu, and L. S. Jiang, "Strain energy evolution and conversion under triaxial unloading confining pressure tests due to gob-side entry retained," International Journal of Rock Mechanics and Mining Sciences, vol. 126, Article ID 104184, 2020.

[2] Z. Z. Zhang, M. Deng, X. Y. Wang, W. J. Yu, F. Zhang, and V. D. Dao, "Field and numerical investigations on the lower coal seam entry failure analysis under the remnant pillar," Engineering Failure Analysis, vol. 115, Article ID 104638, 2020.

[3] N. Zhang, C. L. Han, J. G. Yu, and X. G. Zheng, "Theory and practice of surrounding rock control for pillarless gob-side entry retaining," Journal of China Coal Society, vol. 39, no. 08, pp. 1635-1641, 2014.

[4] Z. Zhang, M. Deng, J. Bai, S. Yan, and X. Yu, "Stability control of gob-side entry retained under the gob with close distance coal seams," International Journal of Mining Science and Technology, vol. 31, no. 2, pp. 321-332, 2021.

[5] N. Zhang, H. Chen, and Y. Chen, "An engineering case of gobside entry retaining in one kilometer-depth soft rock roadway with high ground pressure," Journal of China Coal Society, vol. 40, no. 03, pp. 494-501, 2015.

[6] F. Ju, Z. W. Chen, Q. Zhang, P. Huang, Y. Yu, and L. X. Lan, "Surrounding rock stability control in gob-side entry retaining with solid backfilling in coal mining technology," Journal of Mining \& Safety Engineering, vol. 32, no. 06, pp. 936-942, 2015.

[7] X. M. Sun, X. Liu, G. F. Liang, D. Wang, and Y. L. Jiang, "Key parameters of gob-side entry retaining formed by roof cut and pressure releasing in thin coal seams," Chinese Journal of Rock Mechanics and Engineering, vol. 33, no. 07, pp. 1449-1456, 2014.

[8] H. P. Kang, D. L. Niu, Z. Zhang, J. Lin, Z. H. Li, and M. J. Fan, "Deformation characteristics of surrounding rock and supporting technology of gob-side entry retaining in deep coal mine," Chinese Journal of Rock Mechanics and Engineering, vol. 29, no. 10, pp. 1977-1987, 2010.

[9] Y. L. Tan, F. H. Yu, J. G. Ning, and T. B. Zhao, “Adaptability theory of roadside support in gob-side entry retaining and its supporting design," Journal of China Coal Society, vol. 41, no. 02, pp. 376-382, 2016.

[10] N. Zhang, Z. Y. Zhang, H. Wu, and P. Cao, "Technology and application of reparation in deep gob-side entry retaining," Chinese Journal of Rock Mechanics and Engineering, vol. 33, no. 03, pp. 468-474, 2014.

[11] P. F. Jiang, J. Zhang, and B. Hu, "Mechanical and deformation characteristics of gob-side entry retaining surrounding rock and support methods," Journal of Mining \& Safety Engineering, vol. 33, no. 01, pp. 56-62, 2016.

[12] S. R. Xie, L. Xu, G. C. Zhang, S. J. Li, S. Gong, and L. G. Yang, "Subsidence broken of deep gob-side entry retaining surrounding rock structure with large mining height and its control," Rock and Soil Mechanics, vol. 36, no. 02, pp. 569575, 2015.

[13] Z. Z. Zhang, J. B. Bai, Y. Chen, and M. Li, "Investigation and application analysis of unbalanced bearing characteristics of gob-side entry retaining," Rock and Soil Mechanics, vol. 36, no. 09, pp. 2665-2673, 2015.

[14] C. Wang, Z. S. Du, N. C. Zhang, and D. Y. Qian, "Study on surrounding rock control for mining roadway of the overlying protected seam in ascending de-stressed mining," Journal of Mining and Safety Engineering, vol. 29, no. 02, pp. 220-225, 2012.
[15] J. Zhu, R. H. Wang, and B. Lin, "Reseach on the phenomenon of multiple fracturing and fracture apertures of surrounding rock mass in deep roadway," Journal of China Coal Society, vol. 35, no. 06, pp. 887-890, 2010.

[16] I. W. Farmer, "Stress distribution along a resin grouted rock anchor," International Journal of Rock Mechanics and Mining Sciences \& Geomechanics Abstracts, vol. 12, no. 11, pp. 347351, 1975.

[17] B. Benmokrane, A. Chennouf, and H. S. Mitri, "Laboratory evaluation of cement-based grouts and grouted rock anchors," International Journal of Rock Mechanics and Mining Sciences \& Geomechanics Abstracts, vol. 32, no. 7, pp. 633-642, 1995.

[18] S. C. Li, H. P. Wang, Q. H. Qian et al., "In-situ monitoring research on zonal disintegration of surrounding rock mass in deep mine roadways," Chinese Journal of Rock Mechanics and Engineering, vol. 27, no. 08, pp. 1545-1553, 2008.

[19] X. H. Li, S. Liang, Q. L. Yao, Q. D. Zhai, and L. Zhang, "Analysis on fissure evolving law and roof falling mechanism in roadway with mudstone roof," Journal of China Coal Society, vol. 36, no. 06, pp. 903-908, 2011.

[20] X. Y. Yu, N. Zhang, H. Wu, and B. Y. Li, "A dynamic roof fall risk index for coal mine roadways," Disaster Advances, vol. 6, no. 5, pp. 8-15, 2013.

[21] Q. Wu, L. Chen, B. Shen, B. Dlamini, S. Li, and Y. Zhu, "Experimental investigation on rockbolt performance under the tension load," Rock Mechanics and Rock Engineering, vol. 52, no. 11, pp. 4605-4618, 2019.

[22] Y. L. Lu, L. G. Wang, B. Zhang, and Y. J. Li, "Optimization of bolt-routing time for soft rock roadway," Rock and Soil Mechanics, vol. 33, no. 05, pp. 1395-1401, 2012.

[23] W. J. Wang, G. Peng, and J. Huang, "Research on highstrength coupling support technology of high stress extremely soft rock roadway," Journal of China Coal Society, vol. 36, no. 02, pp. 223-228, 2011.

[24] H. Wu, X. K. Wang, W. J. Yu et al., “Analysis of influence law of burial depth on surrounding rock deformation of roadway," Advances in Civil Engineering, vol. 2020, Article ID 8870800, , 2020.

[25] X. Wu, S. Wang, C. Tian, C. Ji, and J. Wang, "Failure mechanism and stability control of surrounding rock of docking roadway under multiple dynamic pressures in extrathick coal seam," Geofluids, vol. 2020, Article ID 8871925, 16 pages, 2020. 